\title{
Non-prototypical Uses of Personal Pronouns in Chinese
}

\author{
Tunan $\mathrm{Hu}$ \\ Centre for the Study of Language and Cognition \\ Zhejiang University \\ Hangzhou, China 310028
}

\begin{abstract}
Helmbrecht (2015) presents an interesting typological study on the non-prototypical uses of personal pronouns, demonstrating that the form-meaning mismatch involving personal pronouns is essentially discourse-based, in the sense that the referents of personal pronouns dynamically vary with a particular context, and hence some kind of additional pragmatic meaning tends to be encoded into them. Based on his study, Helmbrecht proposes two hypotheses about how the phenomena at issue could be grammaticalized: (i) Plural pronouns may shift to singular ones; (ii) third-person pronouns may shift to second- or first-person ones, but not vice versa. From a more extensive typological perspective, we present in this article some Mandarin Chinese patterns to complement his generalization of personal pronouns.
\end{abstract}

Keywords-non-prototypical use; personal pronoun; reference; grammaticalization

\section{INTRODUCTION}

Helmbrecht (2015) presents an interesting typological study on the non-prototypical uses of personal pronouns, demonstrating that the form-meaning mismatch involving personal pronouns is essentially discourse-based, in the sense that the referents of personal pronouns dynamically vary with a particular context, and hence some kind of additional pragmatic meaning tends to be encoded into them. For instance, a soccer fan can naturally say 'We won the game last night', though $\mathrm{s} / \mathrm{he}$ is not a player of the winning team. Helmbrecht's study also reveals that at least a subset of the non-prototypical uses appears to be stabilized in the diachronic change of personal pronouns. Based on his study, Helmbrecht proposes two hypotheses about how the phenomena at issue could be grammaticalized: (i) Plural pronouns may shift to singular pronouns; (ii) third-person pronouns may shift to second- or first-person ones, but not vice versa. In this article, we present some non-prototypical uses of personal pronouns in Chinese to complement Helmbrecht's generalization as well as to modify his hypotheses of grammaticalization.

\section{NON-PROTOTYPICAL USES OF PERSONAL PRONOUNS IN CHINESE ${ }^{1}$}

The issue of pragmatic referentiality in Chinese has been addressed in the literature (Chen, Huang \& Wu, 2010). Due to the particular focus of this article, we only present the non-prototypical uses of personal pronouns in Chinese, which Helmbrecht's generalization, as given in "Table I", does not seem to apply to.
The abbreviations used in this article is in line with those in Helmbrecht's study: 1, 2, 3 = first, second, third person; SG = singular; PL $=$ plural $; \mathrm{INCL}=$ inclusive $; \mathrm{EXCL}=$ exclusive $;>=$ this symbol translates as 'used as' or 'changed to'; lower case indices in Table 1 indicate the number of tokens of speech act role, e.g. 22-n $=2$ up to $n$ hearer. 
TABLE I. HELMBRECHT'S GENERALIZATION OF NON-PROTOTYPICAL USES OF IMPERSONAL PRONOUNS

\begin{tabular}{|c|c|c|c|c|c|c|c|c|c|c|}
\hline \multirow{2}{*}{\multicolumn{2}{|c|}{$\begin{array}{l}\text { Meaning } \\
\text { Form }\end{array}$}} & \multicolumn{2}{|c|}{ impersonal uses } & \multirow[t]{2}{*}{$1 \mathrm{SG}$} & \multirow[t]{2}{*}{ 1PL } & \multicolumn{2}{|l|}{$2 \mathrm{SG}$} & \multirow[t]{2}{*}{ 2PL } & $3 \mathrm{SG}$ & \multirow[t]{2}{*}{ 3PL } \\
\hline & & generic & specific & & & honorific & & & honorific & \\
\hline \multicolumn{11}{|c|}{$1 \mathrm{SG}$} \\
\hline \multirow{2}{*}{ 1PL } & INCL & + & & & & & \multirow{2}{*}{+} & \multirow[b]{2}{*}{+} & & \multirow{2}{*}{+} \\
\hline & EXCL & & & + & & & & & & \\
\hline \multicolumn{2}{|l|}{$2 \mathrm{SG}$} & + & + & + & & & & & & \\
\hline \multicolumn{2}{|l|}{$2 \mathrm{PL}$} & & & & & + & & & & \\
\hline \multicolumn{2}{|c|}{$3 \mathrm{SG}$} & & & & & + & + & & & \\
\hline \multicolumn{2}{|l|}{$3 \mathrm{PL}$} & + & + & & & + & & & + & \\
\hline
\end{tabular}

\section{A. Non-prototypical Uses of Third-person Pronoun}

\section{1) $3 S G>1 S G$}

Under the dynamic context, the 3SG pronoun ta 'he/she/it', which is prototypically used to refer to a third party, can be employed to mean the speaker himself or herself (which is supposed to be a 1 SG pronoun) in order to enhance the objectivity of the statement expressed by some utterance. The use of ta in (1) below is arguably a typical case in which the speaker exploits the alienation characteristic of a $3 \mathrm{SG}$ pronoun to achieve her purpose.

(1) 凤姐道: “至今珍大哥还抱怨后悔呢。你明儿了他, 好多赔释赔 释, 我年轻, 原没见过世面, 谁叫大爷错委了他呢。”清代曹雪芹 《红楼梦》

Fengjie dao, "zhijin Zhendage hai baoyuan houhui ne. ni Fengji say up to now Cousin Zhen still complain regret PAR 2SG mingge jian le ta, haodai peishi peishi, wo nianqing, tomorrow see ASP 3SG, anyhow apologize apologize 3SG young yuan mei jian guo shimian, shui jiao daye

originally not see ASP aspects of society who make Cousin Zhen cuo wei le ta ne.

mistakenly entrust ASP 1SG PAR

'Fengjie said, "I'm sure Cousin Zhen is still regretting his rashness. When you see him tomorrow, do apologize for me. Tell him he should never have entrusted such a task to someone so young and inexperienced."' (The Dream of Red Mansions by Xueqin Cao)

In (1), the speaker, Fengjie, creates a fictive scenario in which the hearer, her husband, would apologize on her behalf to Cousin Zhen for her fault. Under this circumstance, the speaker directly explains why she botches up the task entrusted by Cousin Zhen, and wants the hearer to verbatim repeat what she said. During the course of her account, the speaker shifts the deictic center from herself to her husband by using a $3 \mathrm{SG}$ pronoun instead of a $1 \mathrm{SG}$ one, which is manifest in the information flow from the speaker-oriented explanation (using the $1 \mathrm{SG}$ pronoun wo 'I') to the heareroriented comment on Cousin Zhen (using the 3SG pronoun ta 'she'). Seen this way, the second 3SG pronoun is not related to Cousin Zhen, but anaphorically connected with the 1SG antecedent, namely Fengjie, the speaker herself. Due to the shift of the deictic center, each part of this excuse performs its own function, respectively: On the one hand, the speaker-oriented explanation shows that it is characteristic of her to courageously admit her own mistake; on the other, the hearer-oriented comment reveals the speaker's intention that she wants to reasonably put the blame for her own fault on Cousin Zhen.

\section{2) $3 S G>3 P L$}

It has been noticed in the literature that $3 \mathrm{SG}$ pronoun can be intended to have a plural meaning (Xu, 1999; Wu and Matthew, 2010; Chen and Wu, 2011). As illustrated in (2), ta should be construed as a collective meaning, referring to zhe bang xiaotou 'the gang of thieves' in topic position.

(2) 这帮小偷, 警处恨不得杀了他。

Zhe bang xiaotou, jingchu henbude sha le ta. this gang thieves police would-rather kill ASP 3PL

'This gang of thieves, the police would rather kill them.' (Xu, 1999:5)

\section{3) $3 S G>$ impersonal generic use}

The impersonal uses of personal pronouns mean that they can be related to an indefinite referent in a particular context (see Kitagawa \& Lehrer, 1990; Biq, 1991 inter alia). In terms of the degree of individuation, Helmbrecht (2015) categorizes this usage into two classes, viz., generic use and specific use: The former means that the personal pronoun refers to a generalized group, whereas the latter relates the personal pronoun to an arbitrary individual. In general, personal pronouns in Chinese can be impersonally used to have a generic meaning, as shown in (3).

(3) 不管是谁, 只要年满十八周岁, 他都有选举权。

Buguan shi shui, zhiyao nian man shibazhousui, ta no matter SHI who, as long as age reach 18 years old generalized group dou you xuanjuquan.

all have suffrage

'Whosoever is over 18 years old has suffrage.'

In (3), ta does not refer to a third party but a generalized group of people meeting the condition of age. This kind of non-prototypical use has not been mentioned in Helmbrecht's study, but it is also quite common in English, especially in some idiomatic expressions, such as 'He that talks much errs much', in which he is apparently related to the generalized group of people instead of a particular third party.

\section{B. Non-prototypical Uses of Second-person Pronouns \\ 1) $2 S G>1 P L$}

Cross-linguistically, a $2 \mathrm{SG}$ pronoun is frequently used to take a 1PL reference. So it is the case with the Chinese ni 'you'. This referential strategy is often employed to effectively establish an intimate relationship between speaker and hearer, as illustrated by (4).

(4) 大家一条心, 死守着我们的都城。我们受平原君的惨痛教训, 即使 你投降, 敌人也要把你斩尽杀绝。所我们都宁肯战死, 也不愿被人屠 杀。郭沫若《虎符》

Dajia yitiaoxin, sishou zhe women de ducheng. everyone be of one mind defend to the last ASP 1PL DE capital women shou Changping de cantong jiaoxun, jishi ni touxiang, 1PL learn Changping DE plainful lesson even if 1PL surrender diren ye yao ba ni zhanjinshajue. Suoyi women dou mingken enemies also will BA 1PL kill all so 1PL all would rather zhansi, yebuyuan bei ren tusha. die in battle than BEI someone slaughter 
'Everyone should be of one mind for defending our capital to the last. We have learned more from Changping's painful lesson. Even if we surrendered, our enemy would still kill us all. So, all of us would rather die in this battle than be slaughtered by them.' (Tiger-shaped Tally by Moruo Guo)

In the context of (4), the speaker, a general, intends to inspire the soldiers to fight against their enemies. To dismiss the idea of surrender completely, the speaker uses the 2SG pronoun non-prototypically to refer to the whole army as an individual indivisible, showing that they are all tied together to survive the battle.

\section{2) $2 S G>3 P L$}

Interestingly, the $2 \mathrm{SG}$ pronoun may also be used as a 3PL one, as shown in (5).

(5) 王国军心里咒骂着, “这些吃着我们的大米、穿着我们的衣服来屠 杀我们的王八蛋! 你就是远在天边, 我也要让炮弹追上你。”杨笑影 《赤子之心》

Wang Guojun xinli zhouma zhe, "zhexie chi zhe women de dami Wnag Guojun silently swear ASP these eat ASP 1PL DE rice chuan zhe women de yifu lai tusha women de wangbadan! wear ASP 1PL DE clothes come slaughter 1PL DE bastard ni jiushi yuanzaitianbian, wo ye yao rang paodan zhuaishang ni." 3PL even if far away 1SG also will let cannonball catch up 3PL 'Wang Guojun swears silently: "These bastards eating our rice and wearing our clothes come to slaughter us! Even if they are far away from me, I will make the cannonball catch up with them also." (The Heart of A Newborn Babe by Xiaoying Yang)

In (5), the speaker expresses his hatred for a group of enemy soldiers who attack him and retreat safely. Because the swear is just the speaker's internal monologue, there is no specific hearer despite the use of $2 \mathrm{SG}$ pronoun ni 'lit. you' in this context. Instead, ni here is anaphorically connected with the constituent zhexie wangbadan 'these bastards' which is supposed to be referred to by a 3PL pronoun. The referential meaning of the $2 \mathrm{SG}$ pronoun could best explain why it is interpreted as a third party here: Using ni in this way, the speaker wants to construct a context in which he is roundly cursing the enemies face-to-face, expressing his hatred and wrath vividly.

\section{Non-prototypical Uses of First-person Pronouns}

\section{1) $1 E X C L . P L>3 S G$}

1EXCL.PL pronoun women 'we' in Chinese can be used to refer to a third party in a context where the speaker bears a close relationship with the intended referent, especially between parents/guardians and children, as in (6).

（6）（王太医）刚要告辞, 只见奶子抱着大姐出来, 笑说: “王老爷也 瞧瞧我们。”清代曹雪芹《红楼梦》

(Wangtaiyi) gangyao gaoci, zhijian naizi baozhe dajie chulai, xiao Doctor Wang be about to leave just see nurse carry Dajie out simle shuo, "Wanglaoye ye qiaoqiao women."

say Mr. Wang too look at 3SG

'Just as Doctor Wang was about to leave, Dajie's nurse carried her out and asked with a smile: "Will Mr. Wang look at us too?" (The Dream of Red Mansions by Xueqin Cao)

In (6), since the patient called Dajie is unable to talk, the nurse serves as her mouthpiece. On the face of it, the 1EXCL.PL pronoun refers to Dajie and the nurse herself, yet it means Dajie only.

\section{2) $1 S G>1 P L$}

In view of the use of the singular pronoun with a plural meaning in the discussions above, it is no surprise at all that the $1 \mathrm{SG}$ pronoun wo 'I' can be non-prototypically used in a plural way, as shown in (7), which is taken from a government report.

(7) 伯承同志是我党我军的大知识分子, 大军事家。《邓小平文选》第 三卷

Bocheng tongzhi shi wo dang wo jun de da zhishifenzi,

Bocheng comrade SHI 1PL party 1PL army DE noted intellectual da junshijia.

noted strategist

'Comrade Bocheng is the noted intellectual and strategist of our party and army.' (Selected Works of Deng Xiaoping, vol. 3)

In (7), wo should be construed as having a collective reading, in the sense that it refers to all members of the party and the army as an impartible entity.

So far, we have discussed the inadequacies of Helmbrecht's typological generalization on European languages. In what follows, we take issue with his argument on the use of 1PL pronoun taking a $2 \mathrm{SG}$ reference in terms of the pragmatic function.

As has been stated in Helmbrecht (2015:183), "this use of the 1PL is patronizing and can be very offensive for the hearer/addressee in certain contexts, because it is implied that the speaker has some authority over the hearer/addressee". We find his argument unconvincing. Consider (8).

（8）老支书: “喜旺啊, 你就别推辞了, 大伙选咱, 那是信任咱。”郡力 《李双双》

Lao zhishu, "Xiwang a, ni jiu bie tuici le. dahuo old branch secretary Xiwang PAR 2SG should not refuse ASP we all xuan zan, na shi xiren zan."

elect 2SG that SHI trust 2 SG

'The old branch secretary said, "Xiwang, you should not refuse. We elect you, because we trust you.' (Li Shuangshuang by Li Shao)

In the context of (8), there is a clear gap of authority, as Helmbrecht argues, between the speaker, the old branch secretary, and the hearer, a common villager named Xiwang. To persuade the hearer to accept the election results, the speaker closes the relationship between them by using 1INCL.PL pronoun zan, which actually does not refer to the two interlocutors here but to the hearer only. Contrary to Helmbrecht's claim, this kind of use effectively eliminates the gap between the interlocutors in order to develop a close relationship. Consider Helmbrecht's examples repeated here as (9) and (10).

(9) Wie fühlen wir uns denn heute? 'How do we feel today?'

(10) Welches von den beiden TV-Geräten nehmen wir denn? 'Which of the two TV-sets do we buy, now?'

(Helmbrecht, 2015:183)

(9) is an utterance in the context of medical consultation whereby he speaker, doctor or nurse, shows that the patient is not a stranger that he or she is responsible for temporarily but a familiar member of their own group. Seen this way, the patronizing and offensive implication claimed by Helmbrecht seems untenable. In (10), which is an utterance between a vendor of TV set and a customer, the use of 1PL pronoun could possibly improve the vendor's chance to make a sale through closing their relationship. 
To sum up, both Helmbrecht's generalization based on European languages and our supplement from Chinese evidence point to the pragmatic-oriented nature of nonprototypical uses of personal pronouns. Nevertheless, there seem to exist some differences between the Chinese language and European languages.

\section{CONCLUSION}

In this article we have shown that Chinese personal pronouns can be non-prototypically used beyond Helmbrecht's typological generalization on European languages. Nevertheless, it should be stressed that we have no intention of devaluing Helmbrecht's study which has not only broadened our perspective on non-prototypical uses of personal pronouns, but redefined the research direction of grammaticalization.

\section{REFERENCES}

[1] Biq, Yung O., 1991. The multiple uses of the second person singular pronoun ni in conversational Mandarin. Journal of Pragmatics. 16 (4), 307-321.

[2] Chen, Jing, Wu, Yicheng, 2011. Less well-behaved pronouns: singular they, in English and plural ta, 'it/he/she' in Chinese. Journal of Pragmatics. 43 (1), 407-410.

[3] Chen, Jing, Huang, Huaxin, Wu, Yicheng, 2010. Aspects of pragmatic referentiality. Journal of Pragmatics.42 (3), 870-874.

[4] Chen Ping, 2009. Aspects of referentiality. Journal of Pragmatics. 41 (8), 1657-1674.

[5] Helmbrecht, Johannes, 2015. A typology of non-prototypical uses of personal pronouns: synchrony and diachrony. Journal of Pragmatics. 88, 176-189.

[6] Wu, Yicheng, Matthews, Steven, 2010. How different are expletive and referential pronouns? A parsing perspective. Lingua. 120 (7), 1805-1820.

[7] Xu, Liejiong, 1999. A special use of the third person singular pronoun. Cahiers de Linguistique - Asie Orientale. 28 (1), 3-22. 